\title{
The Influence of Airflow Inlet Region Modifications on the Local Efficiency of Natural Draft Cooling Tower Operation
}

\author{
Matjaž Dvoršek ${ }^{1}$ - Marko Hočevar2,, - Brane Širok ${ }^{2}$ - Nikola Holeček ${ }^{3}$ - Božin Donevski ${ }^{4}$ \\ 1Termoelektrarna Šoštanj d.o.o., Slovenia \\ 2University of Ljubljana, Faculty of Mechanical Engineering, Slovenia \\ ${ }^{3}$ Gorenje d.d., Slovenia \\ ${ }^{4}$ University St. Kliment Ohridski, Faculty of Technical Sciences, Macedonia
}

\begin{abstract}
We present the influence of the cooling tower airflow inlet region modifications at the Šoštanj 4 thermal power plant on cooling tower local efficiency. Local efficiency change was estimated based on temperature fields of drift eliminators before and after the reconstruction of the cooling tower. Temperature fields were measured with thermal vision method. The local reduction of cooling tower efficiency was analyzed based on phenomenological relations of heat transfer obtained from the selected vertical segment of the cooling tower. The characteristic influence that the reconstruction had on the temperature field was detected on the circumference of the cooling tower. The efficiency reduction was the highest on the periphery of the cooling tower and in particular section it peaked at $2 \%$, while in most part of the area it was below $0.5 \%$. The presented measurement and analysis method enables the estimation of changes in the local efficiency of heat transfer in cooling towers.
\end{abstract}

(C)2011 Journal of Mechanical Engineering. All rights reserved.

Keywords: cooling tower, modifications, local efficiency

\section{INTRODUCTION}

We present an experimental method of local efficiency measurement and analysis to evaluate adequacy of air inlet region modifications in a cooling tower. Other authors use numeric CFD simulations [1] and [2], mathematical modeling [3] or experimental methods [4] in order to estimate cooling tower performance. However, not all methods are able to locally predict efficiency.

Some thermal power plants in the past were built near residential areas, with cooling towers representing a significant source of noise. Later, measures were taken to improve this. However, such measures should not reduce the efficiency of power plants, increase emission of smoke gases or have adverse economic effects.

In thermal power systems, heat is drawn away from the cyclic process to the surroundings by the cooling water. The efficiency of cooling system operation is one of the important factors that influence the efficiency of the whole thermal power system. The amount of heat drawn away by the cooling system is greater than the amount converted to work in the steam process. The amount of drawn-away heat in recently used (new and old) cooling systems varies from 1.3 to 2.5-times the amount of work gained from the system [5] which in any amount of efficiency reduction can result in a significant influence on the efficiency of the entire thermal power system and thus can have a negative impact on the environment.

The quality of heat transfer process can be described by efficiency [6]:

$$
\eta=\frac{t_{w, i}-t_{w, o}}{t_{w, i}-t_{w b, i}}
$$

where $t_{w, i}$ denotes the temperature of inlet water, $t_{w, o}$ is the temperature of outlet water and $t_{w b, i}$ denotes wet-bulb temperature. Temperature $t_{w b, i}$ represents boundary temperature and is the highest possible temperature the air flow through the cooling tower can have at present atmospheric conditions after being heated with water. A temperature difference between the temperature $t_{a, o}$ of the outlet air and boundary temperature $t_{w b, i}$ [7]:

$$
t_{a, o}<t_{w b, i}
$$

is the consequence of deviations, which in most cases are connected with anomalies in the process 
of heat and mass transfer inside cooling towers. Therefore, the information on local temperatures of outlet air is of great value for diagnostics of the local efficiency of cooling towers.

However, the use of efficiency according to Eq. (1) is not appropriate if the outlet humid air is saturated or very near the saturation curve of the Mollier diagram. In the presented experiment, the humid air above the drift eliminators is constantly saturated, therefore, another definition was used as follows.

In the cooling tower, the processes of heat and mass transfer are intensive, as well as the momentum between the sprayed water droplets and humid air. Various analysis methods, which take into account the thermodynamic calculation of cooling towers, are based on Merkel's basic equation [8] and [9]. Here, the efficiency is a function of the exponential dependence of, among others, the ratio between water- and humid air mass flows. However, because the efficiency also depends on geometry, the enthalpy efficiency of vertical segment was defined by the following relation with enthalpies for the case when the air above drift eliminators is fully saturated [10]:

$$
\begin{aligned}
\eta & =\frac{\dot{m}_{d a} h_{(1+x), o}}{\dot{m}_{d a} h_{(1+x), i}+\dot{m}_{w} c_{p w} \cdot t_{w, i}}= \\
& =1-e^{-\tilde{a}\left(\frac{\dot{m}_{w}}{\dot{m}_{a}} \rho \frac{V}{L}\right)^{b}} \approx 1-e^{-a\left(\frac{\dot{m}_{w}}{\dot{m}_{a}}\right)^{b}} .
\end{aligned}
$$

The efficiency can be connected with operating parameters of the process, such as local cooling water flow, local geometric anomalies with changes in the local velocity field of cooling air as a consequence, etc. In the above equation, $\dot{m}_{d a}$ is dry air mass flow, $h_{(1+x), i}$ is specific humid air enthalpy at inlet, $h_{(1+x), o}$ is specific humid air enthalpy at outlet, $\dot{m}_{w}$ is local water mass flow, $\rho$ is air density, $c_{p w}$ is specific heat of water at constant pressure, $V$ is volume and $L$ is the characteristic dimension of lamellate heat exchangers. Constants $\tilde{a}, a$ and $b$ must be selected by an experiment. In order to evaluate the influence of sound protection measures on the efficiency of cooling tower operation, the ratio of mass flows $\dot{m}_{w} / \dot{m}_{a}$ has to be estimated by using temperature distribution on the drift eliminators inside the cooling tower obtained by thermal vision measurements.
Noise in a cooling tower is generated by the falling water. The emitted acoustic power is proportional to the flow rate of water, the velocity of droplets at the moment they fall into water, and water depth in the pool [11]. Most of the noise is emitted through the inlet windows around the circumference of the cooling tower, below the heat exchangers and water collecting channels. The acoustic power emitted by a cooling tower reduces if the depth of its pool decreases [11].

In the following, we will present the applied measures for airflow inlet region modifications of the cooling tower of the Šoštanj 4 thermal power plant to reduce the above mentioned problem. We will estimate local cooling tower efficiencies in accordance with Eq. (3). For measurements, the thermal vision method [7] for measuring the temperature field on the surface of drift eliminators was selected. In order to estimate the influence of airflow inlet region modifications on cooling tower efficiency, temperature measurements were performed prior to and after the reconstruction of the cooling tower.

\section{COOLING TOWER}

The analyzed cooling tower is a natural draft cooling tower of a 275 MW Šoštanj 4 coal power plant. The diameter of the cooling tower at the location of lamellate heat exchangers is $80 \mathrm{~m}$, while the diameter on the ground level is $90 \mathrm{~m}$. The height of the lamellate heat exchanger region is $16.3 \mathrm{~m}$ above the ground. The total height of the cooling tower is $92 \mathrm{~m}$.

Noise generated by the Šoštanj thermal power plant at the selected location of the nearest residential houses exceeded the limit by $4 \mathrm{~dB}(\mathrm{~A})$ during the night [12] to [14]. Measurements were performed in accordance with the requirements for measurements of noise in natural and living environments [12].

In order to identify the noise sources, measurements with an acoustic camera were performed [15]. The identified sources were inlet windows of the cooling tower, which are located on the periphery around the circumference of the cooling tower. Behind the inlet windows, water collecting channels are located, where falling water droplets from lamellate heat exchanger region are collected and directed into the return 
pipe. The water collecting channels are located approximately $12.5 \mathrm{~m}$ above the ground level. However, as water collection channels of the cooling tower are open for inlet air entering from below, the sound is also reflected by the water surface in the pool at the ground level. The schematics of cooling tower structure at the location of water collecting channels is shown in Fig. 1. Airflow inlet region modification was proposed to reduce the noise emission at the source as explained below.

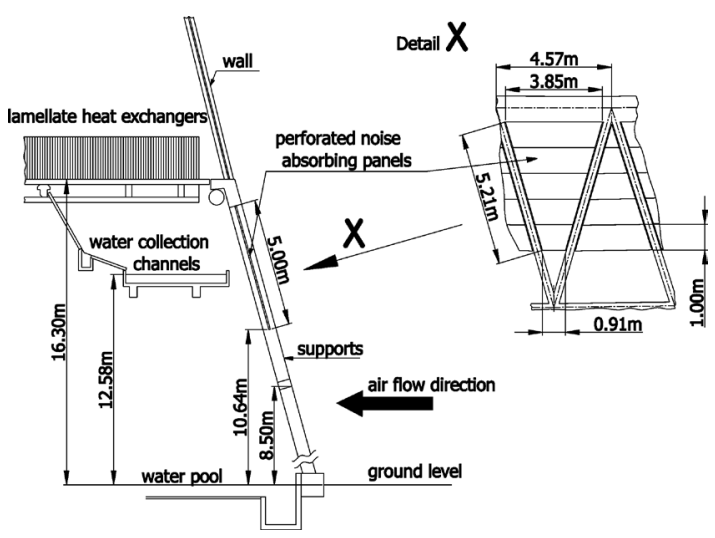

Fig. 1. Schematics of inlet windows region of the cooling tower, modification of airflow inlet region

In the given case, the selected technical solution for airflow inlet region modification was to shut the upper part of the inlet windows, as shown in Fig. 1, using perforated noise absorbing panels. Such a solution should largely eliminate direct noise propagation from inlet windows around the circumference of the cooling tower, while protection from the noise reflected from water pool surface at the ground level would be limited.

Perforated panels made of hard plastic material were used. The height of panels is $5 \mathrm{~m}$, and their thickness is $7 \mathrm{~cm}$. As shown in Fig. 1, panels were set on the periphery of the cooling tower around the height of channels for collecting the cooling water.

Airflow inlet region modification reduced noise level at the location of nearest residential houses [12] and [14]. The results of measurements confirm the adequacy of modifications, such that the legislatively required noise levels were achieved.
However, the modification of airflow inlet region has influenced the mass flow rate of cooling air and its distribution in the cooling tower, therefore changing overall and local efficiencies of cooling tower operation [7] and [10]. The influence of airflow inlet region modification on the thermal efficiency of cooling tower operation is expected above all on the periphery of the cooling tower heat exchange area.

We assume that change in local efficiency can be detected as variation of temperature distribution on the surface of drift eliminators. Variation in temperature distribution on the surface of drift eliminators can be measured with thermal vision method [7]. To estimate the change in local efficiency according to Eq. (3), parameters of cooling tower $a$ and $b$ and mass flow rate ratio $\dot{m}_{w} / \dot{m}_{a}$ must be known. Parameters $a$ and $b$ from Eq. (3) were measured in this particular cooling tower [10] in the selected vertical segment of the cooling tower. We assume that they are valid in the entire cooling tower. Mass flow rate ratio $\dot{m}_{w} / \dot{m}_{a}$ has changed after the airflow inlet region modifications and the change has to be estimated using measurements of temperature of drift eliminators. The measurements of local properties of the cooling tower are required to estimate the dependency between temperature of drift eliminators and mass flow rate ratio $\dot{m}_{w} / \dot{m}_{a}$ for the particular cooling tower. The presentation is given in section 1.1 below.

\subsection{Measurements of Local Properties of Cooling Tower}

Measurements of local properties of the cooling tower enabled the estimation of the relationship among air/water mass flow rate ratio $\dot{m}_{w} / \dot{m}_{a}$ and temperature of drift eliminators. Measurements were performed on the vertical segment of cooling tower. The latter was selected in the region of the cooling tower where geometrical properties are homogeneous. The schemes of the selected segment are presented in Fig. 2. It consists of lamellate heat exchanger located at the bottom, spray element in the central part, and drift eliminators in the upper part of the segment. The following variables were measured: $t_{a, i}$ - temperature of inlet air, $t_{w, i}$ - temperature of inlet water, 
$t_{a, o}$ - temperature of outlet air,

$t_{w, o}$ - temperature of outlet water,

$w_{a, o}$ - humid air velocity,

$\dot{V}_{w, o}$ - cooling water volume flow rate.

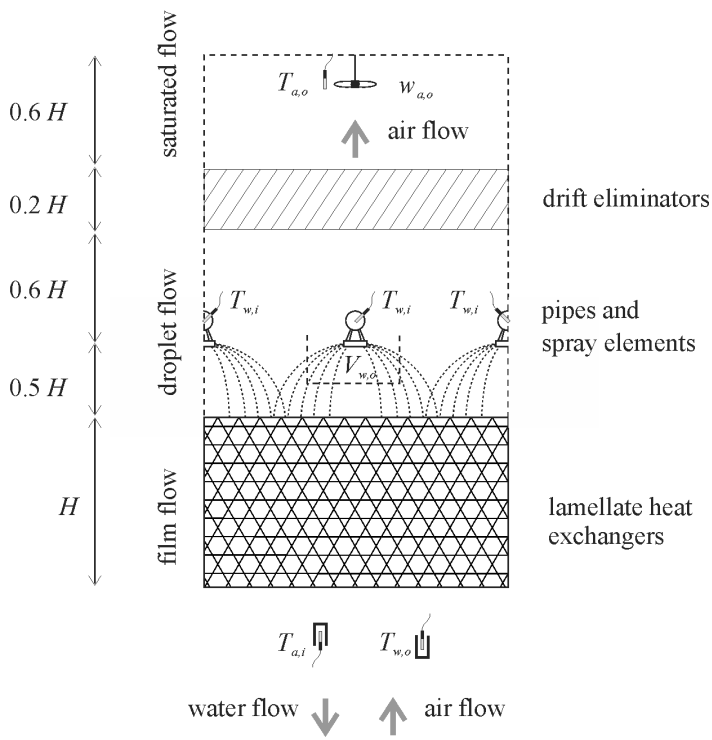

Fig. 2. Schematics of the selected cooling tower segment with location of measurement points

For temperature measurements, 4-wire Pt-100 thermometers were used. The position of thermometers is presented in Fig. 2. Temperatures $t_{w, i}$ were measured inside the pipes in the central and two neighboring locations. Inlet air temperature $t_{a, i}$ was measured in a container which was open from the bottom, while water temperature at fill system outlet $t_{w, o}$ was measured in a container open from the top. The volume of both containers was approximately $0.5 \mathrm{l}$. The uncertainty of temperature measurement was estimated to be less than $0.25^{\circ} \mathrm{C}$. Air velocity measurements were performed using pre-calibrated vane anemometer with low friction bearings lubricated with paraffin oil. The uncertainty of velocity measurement was estimated to $0.1 \mathrm{~m} / \mathrm{s}$. Temperature signal conditioning and data acquisition were performed using Hewlett Packard HP 34970A data acquisition unit, connected to the personal computer. Measurement sampling frequency was $1 \mathrm{~Hz}$, and total acquisition time was $7500 \mathrm{~s}$.

Cooling water volume flow rate $\dot{V}$ was measured using volumetric method. Water volume flow rate was measured at the outlet spray nozzle using a vessel with the volume of 301 . Time, required to fill the vessel was measured. Care was taken that no water from neighboring spraying elements entered the vessel and that no water from measured spray element was lost. Cooling water volume flow rate was measured before the sampling of other variables was started.

Inlet air humidity was determined on the basis of dry- and wet-bulb measurements. Humidity, as well as other ambient air parameters were observed in selected locations in $30 \mathrm{~s}$ intervals.

All the equipment used in experiments was pre-calibrated. The systematic measurement uncertainty met the requirements of the standard for measuring cooling tower characteristics [16].

Measurements of the local properties of the cooling tower were performed in seven measurement points in which cooling water volume flow rates $\dot{V}_{w, o}$ were constant at 4.2 and $4.7 \mathrm{l} / \mathrm{s} / \mathrm{m}^{2}$, while other variables varied. The airflow velocity $w_{\mathrm{a}, \mathrm{o}}$ ranged from $0.95 \mathrm{~m} / \mathrm{s}$ to 2.3 $\mathrm{m} / \mathrm{s}$, while mass flow rate ratio $\dot{m}_{w} / \dot{m}_{a}$ ranged from 1.59 to 3.42 . Inlet air humidity ranged from 42 to $51 \%$, inlet air temperature $t_{a, i}$ ranged from 15.3 to $17.5{ }^{\circ} \mathrm{C}$, outlet air temperature $t_{a, o}$ ranged from 23.1 to $33.2^{\circ} \mathrm{C}$, sprayed water temperature $t_{w, i}$ ranged from 25.5 to $34.0{ }^{\circ} \mathrm{C}$, and temperature of the water at fill system outlet $t_{w, o}$ ranged from 17.4 to $27.4^{\circ} \mathrm{C}$.

\section{THERMAL VISION MEASUREMENTS OF DRIFT ELIMINATORS}

Thermal vision method enables to measure the temperature field of drift eliminators inside natural draft cooling towers. The measurement system is shown in Fig. 3.

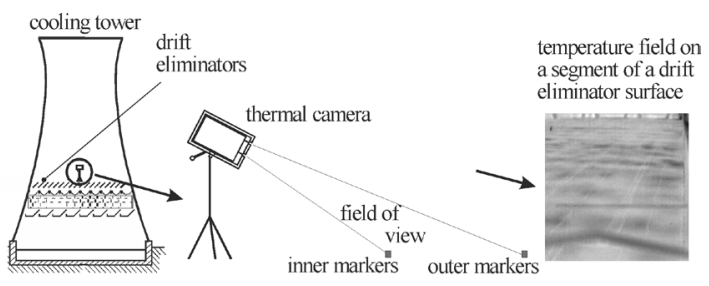

Fig. 3. Schematics of the thermal vision method for temperature measurements of drift eliminators inside the cooling tower 
During the cooling tower operation, the fluid above the drift eliminators comprises air and water either in gaseous phase or in form of small droplets. Humid air and droplets generally impair the transmission of infrared electromagnetic radiation [17]. Širok et al. [7] have shown that temperature measurements inside a cooling tower using an infrared camera operating in 7.5 to 13 $\mu \mathrm{m}$ range were within a frame of measurement uncertainty with temperature measurements using precise RTD sensors up to the distance of $25 \mathrm{~m}$.

\subsection{Thermal Camera}

Temperature measurements of the surface of drift eliminators were performed by an AGEMA 570 infrared sensitive camera, which operated in far-infrared range of wavelengths between $7.5 \mu \mathrm{m}$ and $13 \mu \mathrm{m}$. It had a built-in $24^{\circ}$ lens with spatial resolution $1.3 \mathrm{mrad}$. The thermal camera applied a Focal Plane Array (FPA) detector, which consisted of a matrix with $320 \times 240$ elements/pixels. The accuracy of the camera is $\pm 2{ }^{\circ} \mathrm{C}$ according to the manufacturer's specifications, while the thermal sensitivity is $0.15 \mathrm{~K}$. Thermal images were recorded to a PC card which was inserted in the camera.

\subsection{Thermal Camera Installation and Measurement Procedure}

The thermal camera was enclosed in a protective container (Fig. 3) which was continually purged with the compressed dry air supplied by a compressor through a hose from the outside of the cooling tower. This was necessary in order to protect the thermal camera from high relative humidity of the air (close to $100 \%$ ) and condensation inside the cooling tower. The lens of the thermal camera was directed coaxially through an orifice in the protective container, while the camera lens was located $5 \mathrm{~mm}$ behind the orifice inside the container. The orifice was slightly larger in diameter than the camera lens, so a narrow coaxial gap was formed between the lens of the thermal camera and the wall of the orifice. The compressed air left the protective container through this gap, thus preventing the condensed water particles from building up on the thermal camera lens. Flexible transparent foil was mounted on the backside of the protective container to enable access to controls on the thermal camera.

The thermal camera, together with its protective container, was mounted on an adjustable stand as depicted in Fig. 3. The stand was located in the middle of the cooling tower. The height of the stand was $2.3 \mathrm{~m}$ above the surface of drift eliminators. Thermal images were acquired so that the camera and its protective container were rotated around their vertical axis in steps of approximately $22^{\circ}$. The temperature field of the whole surface of drift eliminators of the cooling tower was covered in 16 segments corresponding to different thermal camera rotations in the horizontal plane.

The positioning of thermal camera in the meridian plane was carried out with the aid of markers and intrinsically incorporated objects of the cooling tower, like wall structure, pathways and fences. As markers, cold objects approximately $90 \times 180 \mathrm{~mm}$ in size was used. They were placed at different positions on the drift eliminator plane of the cooling tower where access was possible; otherwise, objects that are intrinsically incorporated in the cooling tower itself were used. Positions of markers were measured by measuring tape, therefore their exact position was known. Positions of intrinsically incorporated objects were recognized based on technical drawings. Due to low temperature, markers were visible on thermal images, while intrinsically incorporated objects were visible because of different emissivity or temperature. Four markers were used at each thermal camera position: two inner ones - close to the lower edge of camera's field of view, and two outer ones close to the upper edge of camera's field of view near the circumference of the cooling tower. The same markers were used in neighboring segments of the cooling tower, whereas in segments close to the pathways markers were put as close to the pathways as possible. Markers enabled the spatial transformation from acquired thermal images to the temperature field above the drift eliminators in cooling tower coordinates.

Based on the analysis of acquired thermal images, projective transformation was used for each thermal camera position to transform temperature information to real cooling tower coordinates. Projective transformation with 
bicubic interpolation for temperature was selected as it is suitable for tilted images and because straight lines in original images are transformed to straight lines on the transformed image. Temperatures of all 16 measured segments were then combined into a single temperature field of drift eliminators for the complete cooling tower.

\subsection{Environmental Conditions}

The temperature measurements with the thermal vision method were carried out before and after the installation of sound insulation panels. During the measurements, performed before the installation of sound insulation panels, the following average environmental conditions were recorded: inlet air temperature $t_{a, i} 22.4{ }^{\circ} \mathrm{C}$, inlet air humidity $43 \%$, outside air velocity $1.6 \mathrm{~m} / \mathrm{s}$, inlet water temperature $t_{w, i} 31.2{ }^{\circ} \mathrm{C}$ and outlet water temperature $t_{w, o} 24.5^{\circ} \mathrm{C}$.

Measurements after the installation of sound insulation panels were performed at the following average environmental conditions: inlet air temperature $t_{a, i} 9.3{ }^{\circ} \mathrm{C}$, inlet air humidity $81 \%$, outside air velocity $2.9 \mathrm{~m} / \mathrm{s}$, inlet water temperature $t_{w, i} 23.0{ }^{\circ} \mathrm{C}$ and outlet water temperature $t_{w, o} 7.9^{\circ} \mathrm{C}$.

\section{RESULTS AND DISCUSSION}

Two-dimensional temperature measurements in the plane of drift eliminators were performed using thermal camera, and for the analysis of efficiency they were used with Eq. (3), which gives local efficiency in each vertical cooling tower segment. Each measured temperature on the plane of drift eliminators is linked to the properties of cooling tower's vertical segment by Eq. (3) through dependency presented in Fig. 4. Temperature measurements in the two-dimensional plane of drift eliminators therefore supplement the local measurement of cooling tower characteristics in the single vertical segment. By assuming that local characteristics measured in the single vertical segment of the cooling tower are valid in the entire cooling tower, the presented analysis procedure enables the analysis of local efficiency for the entire cooling tower.
The method used is based on an experimental modeling approach, which is quite common when analysing cooling towers. While the analysis of the same problem was not found in the available published literature, other authors deal with cooling tower design modifications for various reasons like guiding plates for cross-wind conditions [2] and [4].

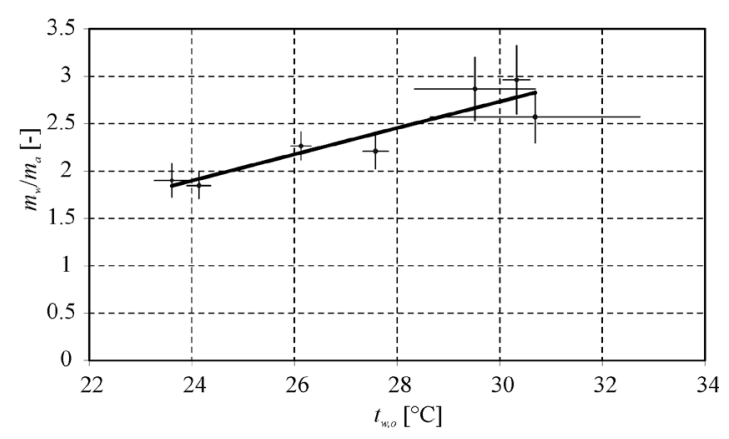

Fig. 4. Mass flow rate ratio $\dot{m}_{w} / \dot{m}_{a}$ dependence on temperature of drift eliminators $t_{a, o}$

Measurements in cooling tower are limited due to cooling tower size, complexity and dependence on requirements of power generation system. Usually it is not possible to vary one parameter and set all other parameters constant. Scatter of measurements is usually large due to continuous change of most of environmental parameters. However, due to extreme large size of the system, variables change is slow and the number of measurement points low, making it difficult to evaluate the influence of environmental and other parameters. In our case it is thus impossible to show influence of environmental parameters on mass flow ratio and efficiency apart from those that were $\dot{m}_{w} / \dot{m}_{a}$ actually measured.

\subsection{Measurement Uncertainty of Temperature Measurements of Drift Eliminators}

Temperature of drift eliminators was measured using thermal camera as presented in sections 2.1 and 2.2. Absolute measurement uncertainty of the thermal camera is in the range of few ${ }^{\circ} \mathrm{C}$, and is larger than required for measuring local efficiency change. The influence of absolute measurement uncertainty of the camera is depicted in Fig. 5, which shows the temperature 
measurements of drift eliminators before the airflow inlet region modifications. In Fig. 5, noncontinuities between 16 measured sections of the cooling tower indicate the influence of absolute measurement uncertainty.

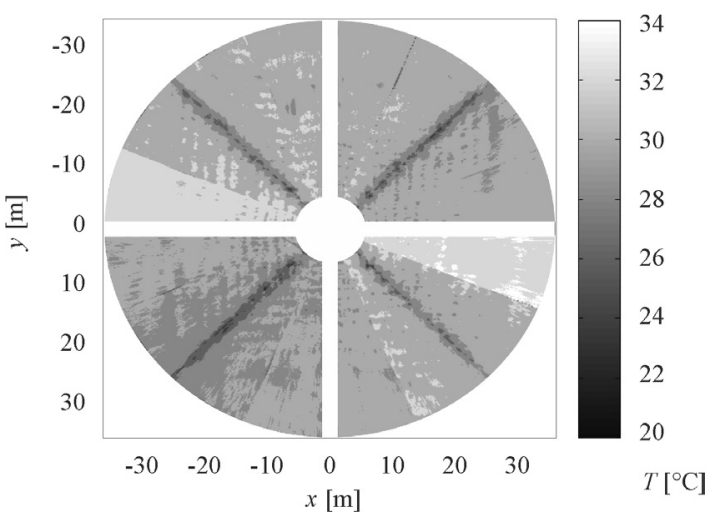

Fig. 5. Results of temperature distribution measurements inside the cooling tower before the installation of sound absorption panels; white regions represent passages

To tackle the issue of measurement uncertainty, absolute temperature measurements of drift eliminators were used only for the case of measurements before the airflow inlet region modifications. Relative measurements between the inner and outer part of cooling tower were used in the case of measurements after the airflow inlet region modifications. It was presumed that flow properties and temperatures in the middle of the cooling tower far from the position of the airflow inlet region modifications do not change. The boundary between both regions was selected at the half of the cooling tower radius. Measurements after the airflow inlet region modifications were used only to estimate the temperature change at the perimeter relative to the inner part of the cooling tower. Using this relative approach, measurement uncertainty can be estimated by the thermal sensitivity of thermal camera, which is $0.15^{\circ} \mathrm{C}$. In addition, the results in [7] indicate that the uncertainty of thermal measurement including the propagation through the saturated air in the cooling tower is below $0.4{ }^{\circ} \mathrm{C}$.

\subsection{Estimation of Cooling Tower's Local Properties}

Under the assumption that outlet cooling air temperature is the same as the temperature of the surface of drift eliminators, local efficiency in the cooling tower can be estimated according to the model represented by Eq. (3). According to Eq. (3), air and water flow rates are required for the estimation of local efficiency, but they can only be measured with difficulty and only in selected locations. Instead, the temperature of drift eliminators was used to estimate the local efficiency. The available literature only revealed the work of Kloppers [18] who experimentally evaluated the local efficiency of cooling towers based on the measurements of outlet air temperature. The measurement procedure in [18] was similar to the one presented here. The manufacturers of cooling tower equipment among others use the temperature of drift eliminators to estimate the upgrade capabilities of existing cooling towers.

The estimation of the properties of the cooling tower was performed as explained in section 1.1. Fig. 4 shows the measured relationship among air/water mass flow rate $\dot{m}_{w} / \dot{m}_{a}$ and temperature of drift eliminators. Measurements were performed in seven measurement points. The latter were selected in a way that the operational parameters of the plant and cooling tower were constant, while it was not possible to control environmental parameters. This resulted in a large deviation of measured points from the fitted line in Fig. 5. The most important environmental parameter is inlet air humidity. Inlet air relative humidity was ranged from 42 to $51 \%$ in the case measuring the local characteristics of the cooling tower, while it was $43 \%$ while measuring the temperature of drift eliminators for the measurement of efficiency. Unfortunately, environmental variables cannot be controlled; it is only possible to postpone measurements until appropriate environmental parameters are available. However, this can only be done in a limited time interval because of the complexity of measurements.

If more measurement data were available, the fitted line could be exchanged for a more elaborate relation, taking into account other 
parameters like ambient temperature, humidity, wind speed and direction, power plant output, etc. Given the complexity of measurements and high dimensionality of the problem, the results in Fig. 4 present the cooling tower characteristics fairly well. The relation in Fig. 4 is also limited to the construction of the observed cooling tower, although it can be presumed that the general trend of the presented dependence is characteristic of all natural draft cooling towers. In this particular case, the presented relation can be used for the estimation of the influence of airflow inlet region modifications on local efficiency of the cooling tower.

\subsection{Temperature of Drift Eliminators and Cooling Tower's Local Efficiency}

The temperature of drift eliminators before airflow inlet region modifications is presented in Fig. 5. No spatial filtering method was used for presentation in Fig. 5. From the temperature field of drift eliminators, the local efficiency before the airflow inlet region modifications was estimated using Eq. (3) and mass flow rate ratio $\dot{m}_{w} / \dot{m}_{a}$ in Fig. 4. The local efficiency before the installation of sound protection panels is shown in Fig. 6 .

In order to estimate the difference in efficiencies from both measurements before and after the airflow inlet region modifications, we have to consider that the measurement uncertainty of the camera is high compared to expected changes in temperature distribution, and that both measurements were performed at different environmental conditions. Therefore, an approach was used which is based on the difference between the temperature in outer region and the temperature in inner region of the cooling tower as explained in section 3.1. Temperature differences in the inner and outer region of segments of both cases prior to and after modifications were then used with data from the local measurement of cooling tower properties according to the procedure presented in section 1.1.

A change in local efficiency after the installation of sound absorption panels is shown in Fig. 7.

Local efficiency after the installation of sound absorption panels decreased up to 0.02 . The changes are localized to the circumference of the cooling tower. In addition, in some locations on the circumference, changes in efficiency were not recorded. This is not surprising, as flow and thermal properties around the circumference often differ from those in the middle of the cooling tower [3]. The current cooling tower also has lamellate heat exchangers installed high above the ground compared to it's diameter and overall height, as can be seen in Fig. 1. Such configuration helps reducing the decrease in local efficiency. Other authors have provided mixed results for different cooling tower modifications [2] and [4], however, none of them studied the airflow inlet region modifications at the location of water collection channels.

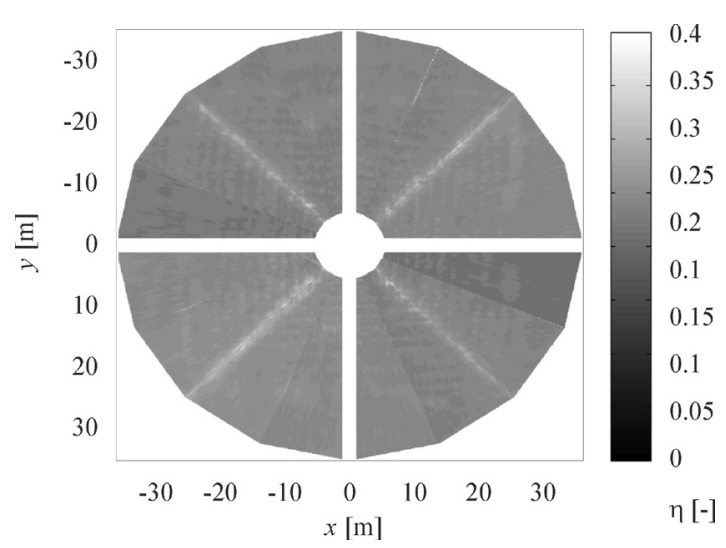

Fig. 6. Local cooling tower efficiency before the installation of sound absorption panels; white regions represent passages

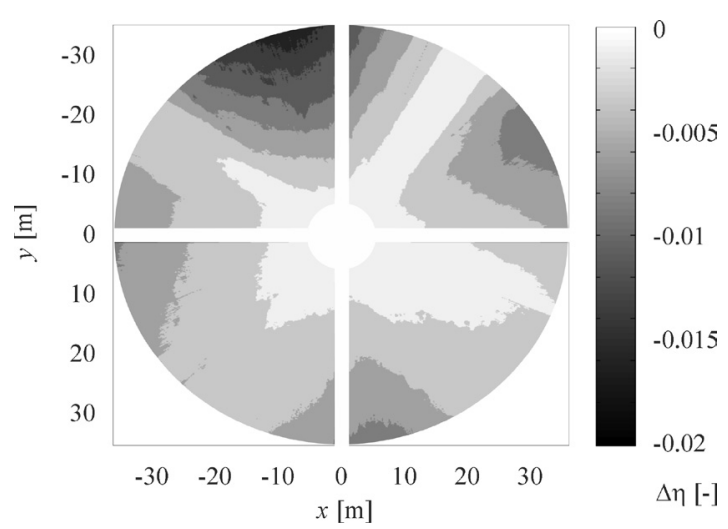

Fig. 7. Decrease of local efficiency after the installation of sound absorption panels; white regions represent passages 
The overall decrease of local efficiency of up to 0.02 can be generally estimated as small. This is in agreement with the results presented in [19], which show that the effect of inlet height on radial non-uniformity of cooling tower properties is very small in comparison with the effect of water flow rate change. Water flow rate did not change with the airflow inlet region modifications. Also, power plant operators did not notice any decrease in overall power plant performance including inlet/outlet cooling water temperature difference from the cooling tower. Operator's estimation was not systematically evaluated.

The presented method allows an evaluation of the cooling tower performance for the case of modifications like the airflow inlet region modifications. Temperature measurements of drift eliminators using thermal camera are fast and easy, while measurements of local properties of cooling tower require much more effort, as emphasized also in [19]. In the cooling towers, where the dependency between mass flow rate ratio $\dot{m}_{w} / \dot{m}_{a}$ and temperature of drift eliminators is unknown, operators may only use thermal measurements of temperature eliminators to regularly check the cooling tower operation. In general, high local temperature represents the locations of lower heat transfer efficiency.

In addition to the above mentioned benefits, the following most important drawbacks of the method must be mentioned: (i) measured data represents the temperature on the surface of drift eliminators and no further information about temperature distribution inside the lamellate heat exchangers can be directly established using thermal vision method; (ii) estimation of local efficiency is limited due to the necessity to use experimentally derived constants $a$ and $b$ for use in Eq. (3), which is valid only for a selected cooling tower and for limited interval of operational and environmental parameters; (iii) use of experimentally derived relationship between mass flow ratio $\dot{m}_{w} / \dot{m}_{a}$ and temperature of drift eliminators according to Fig. 5, which is also valid for the selected cooling tower and for the limited interval of operational and environmental parameters, which usually do not match environmental parameters during measurements either before or after modifications. Among environmental parameters, inlet air humidity was estimated as the most important one.

Verification of the local efficiency decrease cannot be measured using any other method known to us except local measurement of all variables from Eq. (3), which is difficult, time consuming and therefore not feasible. We see measurements in accordance with [16] or numerical modeling [1] and [19] as one of the possible comparisons.

\section{CONCLUSIONS}

Temperature measurements of drift eliminators were performed before and after the installation of sound protection panels. Based on these results, changes in local efficiencies were estimated. Results show a slight decrease of local efficiency at the circumference of the cooling tower, while in general decrease is small.

Verification of the estimated changes of local efficiency can also be determined using measurements performed in accordance with [14].

\section{REFERENCES}

[1] Al-Waked, R., Behnia, M. (2006). CFD simulation of wet cooling towers. Applied Thermal Engineering, vol. 26, no. 4, p. 382395.

[2] Al-Waked, R., Behnia, M. (2007). Enhancing performance of wet cooling towers. Energy Conversion and Management, vol. 48, p. 2638-2648.

[3] Williamson, N., Armfield, S., Behnia, M. (2008). Numerical simulation of flow in a natural draft wet cooling tower - The effect of radial thermofluid fields. Applied Thermal Engineering, vol. 28, no. 2-3, p.178-189.

[4] Wang, K., Sun, F. Z., Zhao, Y. B., Gao, M., Ruan, L. (2010). Experimental research of the guiding channels effect on the thermal performance of wet cooling towers subjected to crosswinds - Air guiding effect on cooling tower. Applied Thermal Engineering, vol. 30 , no. 5 , p. 533-538.

[5] El-Wakil, M.M. (1985). Powerplant Technology, McGraw-Hill, New York.

[6] Ibrahim, G.A., Nabhan, M.B.W., Anabtawi, M.Z. (1995). An investigation into a falling film type cooling tower. International 
Journal of Refrigeration, vol. 18, no. 8, p. 557-564.

[7] Širok, B., Hočevar, M., Bajcar, T., Blagojević, B., Dvoršek, M., Novak, M. (2006). Thermovision Method for Diagnostics of Local Characteristics of Natural Draft Cooling Towers. Instrumentation Science \& Technology, vol. 34, no. 3, p. 289-304.

[8] Hampe, E. (1975), Kühltürme, VEB Verlag für Bauwessen, Berlin.

[9] Heyns, J.A., Kröger, D.G. (2010). Experimental investigation into the thermal-flow performance characteristics of an evaporative cooler. Applied Thermal Engineering, vol. 30, no. 5, p. 492-498.

[10] Širok, B., Blagojević, B., Novak, M., Hočevar, M., Jere, F. (2003). Energy and mass transfer phenomena in natural draft cooling towers. Heat transfer engineering, vol. 24, no. 3, p. 66-75.

[11] Presnov, G.V., Zroichikov, N.A., Galas, I.V., Patakin, A.A., Moskvin, A.G., Lisitsa, V.I., Morozova, E.A. (2006). An efficient method for suppressing noise from the cooling tower at OAO Mosenergo's TETs-23 cogeneration station. Thermal Engineering, vol. 53, no. 11, p. 910-912.

[12] Decree on noise in the natural and living environment (1995). Official Gazette of the Republic of Slovenia, vol. 45, p. 3530-3535. (in Slovene)
[13] Deželak, F. (2005). Report on measurements and expert opinion - noise in the natural and living environment. Technology report LFIZ 05123, ZVD, Ljubljana. (in Slovene)

[14] Deželak, F. (2006). Report on measurements of noise in environment - noise in the natural and living environment. Technology report LFIZ-20060172-FD/M, ZVD, Ljubljana. (in Slovene)

[15] Deželak, F. (2006). Results of recording with acoustic camera. Technology report LFIZ-20060132-FD/M, ZVD, Ljubljana (in Slovene).

[16] DIN (VDI Code of practice) 1947 (1989). Thermal performance acceptance testing of water cooling towers. Deutsches Institut Für Normung E.V., Berlin.

[17] Gayo, E., de Frutos, J. (1997). Interference filters as an enhancement tool for infrared thermography in humidity studies of building elements. Infrared Physics \& Technology, vol. 38, no. 4, p. 251-258.

[18] Kloppers, J.C. (2003). A critical evaluation and refinement of the performance prediction of wet-cooling towers. $\mathrm{PhD}$ thesis, University of Stellenbosch, Stellenbosch.

[19] Hawlader, N.A., Liu, B.M. (2002). Numerical study of the thermal-hydraulic performance of evaporative natural draft cooling towers. Applied Thermal Engineering, vol. 22, no. 1, p. 41-59. 